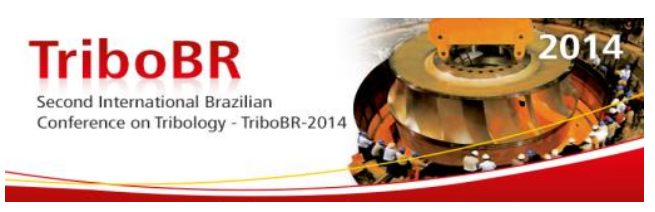

\title{
CAVITATION EROSION DAMAGE OF METALLIC MATERIALS IN ROTATING DISK TESTING*
}

\author{
José Divo Bressan ${ }^{1}$ \\ Marcos Antunes Klemz ${ }^{2}$ \\ Gil Bazanini3
}

\begin{abstract}
Present work examines material surface damage by cavitation erosion of metals or the wear phenomenon from water bubbles collapse near the metallic surface. Material surface damage by cavitation erosion is due to wear mechanisms of liquid micro-jets impingement and shock waves. Experimental cavitation in tap water was investigated, using the proposed new design of compact rotating disk equipment. In this device, a rotating disk with cavitation inducers and specimens fixed on it ran in tap water to provide cavitating flow at constant high speed of $47.9 \mathrm{~m} / \mathrm{s}$ similar to service conditions in pumps and propellers. Two types of cavitation inducers in the rotating disk were investigated: through-holes and pins. Carburized cast iron, aluminum, brass and bronze specimens were tested in this device. The cavitation damage mechanisms were observed by scanning electron microscope. Surface damage in the specimens was measured by mass loss and plotted in graphs of mass loss versus running time. After 25 hours testing, the specimens surface showed pitting formation and mass loss. All specimens presented surface damage: pit diameter size was about 100 or 150 to 300 micron. In aluminum specimen, damages by burned pit formation and plastic deformation could be seen, however, the mass loss was lower than the expected, possibly due to alumina film formation. Present equipment had quite good test reproducibility when compared with results from literature.
\end{abstract}

Keywords: Cavitation testing; Cavitation erosion; Non-ferrous metals; Scanning electron microscope.

1 Ph.D. in Mech. Eng., Department of Mechanical Engineering, University of Santa Catarina State (Udesc Joinville), Joinville, SC, Brazil; dem2jdb@joinville.udesc.br.

2 Mech. Eng., Department of Mechanical Engineering, University of Santa Catarina State (Udesc Joinville), Joinville, SC, Brazil

3 Dr. in Mech. Eng., Department of Mechanical Engineering, University of Santa Catarina State (Udesc Joinville), Joinville, SC, Brazil.

* Technical contribution to the $2^{\text {nd }}$ International Brazilian Conference on Tribology - TriboBR 2014, November $3^{\text {rd }}$ to $5^{\text {th }}$, 2014, Foz do Iguaçu, PR, Brazil. 


\section{INTRODUCTION}

Material surface damage by cavitation erosion is one main concern in pump blades and propellers design. The cavitation phenomena comprise the formation, growth and collapse of air and vapor bubbles inside liquids. Bubbles formation in liquids can be divided into two distinct processes of liquid-vapor phase change: cavitation and boiling. One way of distinguishing these two processes is to define cavitation as bubble nucleation or inception in a flowing liquid when the local pressure drops below its vapor pressure at constant temperature, while boiling is the process of bubble generation that occurs when the local temperature is raised above the saturated liquid-vapor temperature and under constant pressure [1]. Moreover, the cavitation phenomenon includes the complete bubble cycle, from its nucleation up to its complete disappearing. Cavitation is, as well known, responsible for material surface damages in metallic and non-metallic solid parts and structures in liquid mediums, remarkably in water. Such bubbles, or cavities, nucleate from micro-bubbles of air present in the liquid medium or when the local pressure drops below its vapor pressure at roughly constant temperature [1].

Therefore, cavitation erosion is a complex phenomenon that involves complicated unsteady fluid flow and is difficult to model. The nondimensional parameter which is commonly used to characterize cavitating fluid flows is the cavitation parameter $\sigma$,

$$
\sigma=\frac{P_{\infty}-P_{v}}{\frac{1}{2} \rho_{L} U^{2}}
$$

where $U$ is the speed of the undisturbed fluid flow, $\rho_{L}$ is the liquid density, $P_{\infty}$ is the static pressure of the undisturbed liquid, and $P_{v}$ is the vapour pressure of the liquid. The cavitation number measures the resistance of fluid flow to cavitation. Bubble nucleation is expected to occur at the incipient cavitation number $\sigma_{i}$ when the local pressure drops below $P_{v}$. For cavitation number higher than $\sigma_{i}$, cavitation is less likely to occur. On the other hand, for $\sigma$ lower than $\sigma_{i}$, cavitation is more likely to take place. Obviously, one cannot expect that a single parameter would describe completely such a complex phenomenon of cavitating flow. Anyway, from experimental observations, sufficiently large positive values of $\sigma$ correspond to noncavitating flow. As $\sigma$ decreases below $\sigma_{i}$, the flow changes from incipient to full cavitating regime. The limiting value for $\sigma$ is zero, because it implies that the liquid is at the boiling point everywhere.

As the bubble growths, it is filled by liquid vapor when pressure and temperature of the internal mixture are close to the vapor pressure and temperature of the surrounding liquid, until attaining an equilibrium radius [2]. After that, the bubble or bubbles, begin collapsing and may disappear or initiate a new cycle, this may then be repeated for several times until the bubbles disappear [2].

When bubbles collapse near solid surfaces, cavitation damage may occur due to two already known erosion mechanisms: liquid micro-jets impingement and shock waves $[1,3,4]$. Micro-jets are caused by bubble splitting into two parts near the solid surface (influenced by the surface close to it. A good visualization of the phenomenon at the final stages of collapse can be seen in Shervani-Tabar et al. [5] and shock waves results from instantaneous variable pressure fields (collapse duration is of about microseconds) [3, 4]. In the final stage of bubble collapse,

* Technical contribution to the $2^{\text {nd }}$ International Brazilian Conference on Tribology - TriboBR 2014, November $3^{\text {rd }}$ to $5^{\text {th }}$, 2014, Foz do Iguaçu, PR, Brazil. 


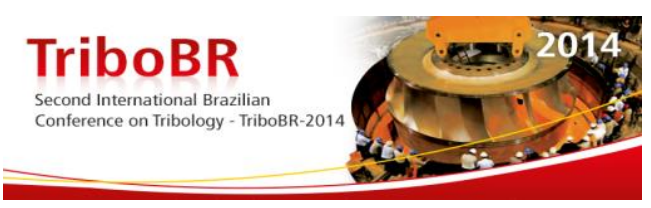

temperature can be as high as $6700 \mathrm{~K}$. These micro-jets and shock waves are responsible for cavitation erosion or material loss from the surface, basically by fatigue failure.

\section{EXPERIMENTAL SET UP AND APPARATUS}

The new design of cavitation apparatus proposed by Bazanini and Bressan [6] consists of a water chamber inside which a metallic disk rotates. On the disk surface there are cavity inducers, which can be through-holes or protruding pins, and also the specimens. The disk is fixed on the rotating shaft and can be removed to attach the specimens. A glass cover is mounted on the chamber to visualize the flow and bubble formation inside it (see Figure 1).

The purpose of the device is to create cavitation bubbles similar to service conditions similar to those found in pump impellers and propellers. The generated bubbles promoted by the bubble inducers and its collapse will be responsible for the cavitation erosion of specimens fixed on the disk surface. The rotating disk, of 250 $\mathrm{mm}$ in diameter, showing the cavitation chamber and bubbles formation can be observed in Figure 1 below.

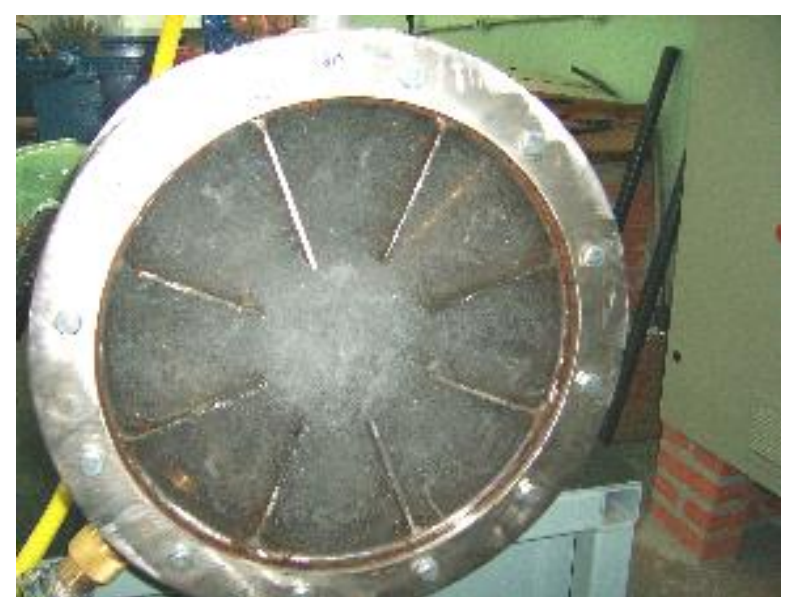

Figure 1. Cavitation erosion apparatus employed in present study [6], with cloud of bubbles (cavitation number $\sigma=0.082$ ).

For cooling purpose to maintain constant temperature and for constant fresh tap water supplying into the system, a water reservoir was used to circulate the water inside the equipment chamber. Inlet and outlet piping are provided by control valves and a filter to protect the chamber from small particles resulting from the cavitation erosion process.

Employing the "intermediary casing", commonly used to connect pumps to electric motors, it was possible to avoid the use of bearings and coupling components, resulting in a shorter shaft and a compact disk apparatus. That is, the chamber and rotating disk now replaces the pump, improving the experiments that are performed in a very realistic condition.

* Technical contribution to the $2^{\text {nd }}$ International Brazilian Conference on Tribology - TriboBR 2014, November $3^{\text {rd }}$ to $5^{\text {th }}$, 2014, Foz do Iguaçu, PR, Brazil. 

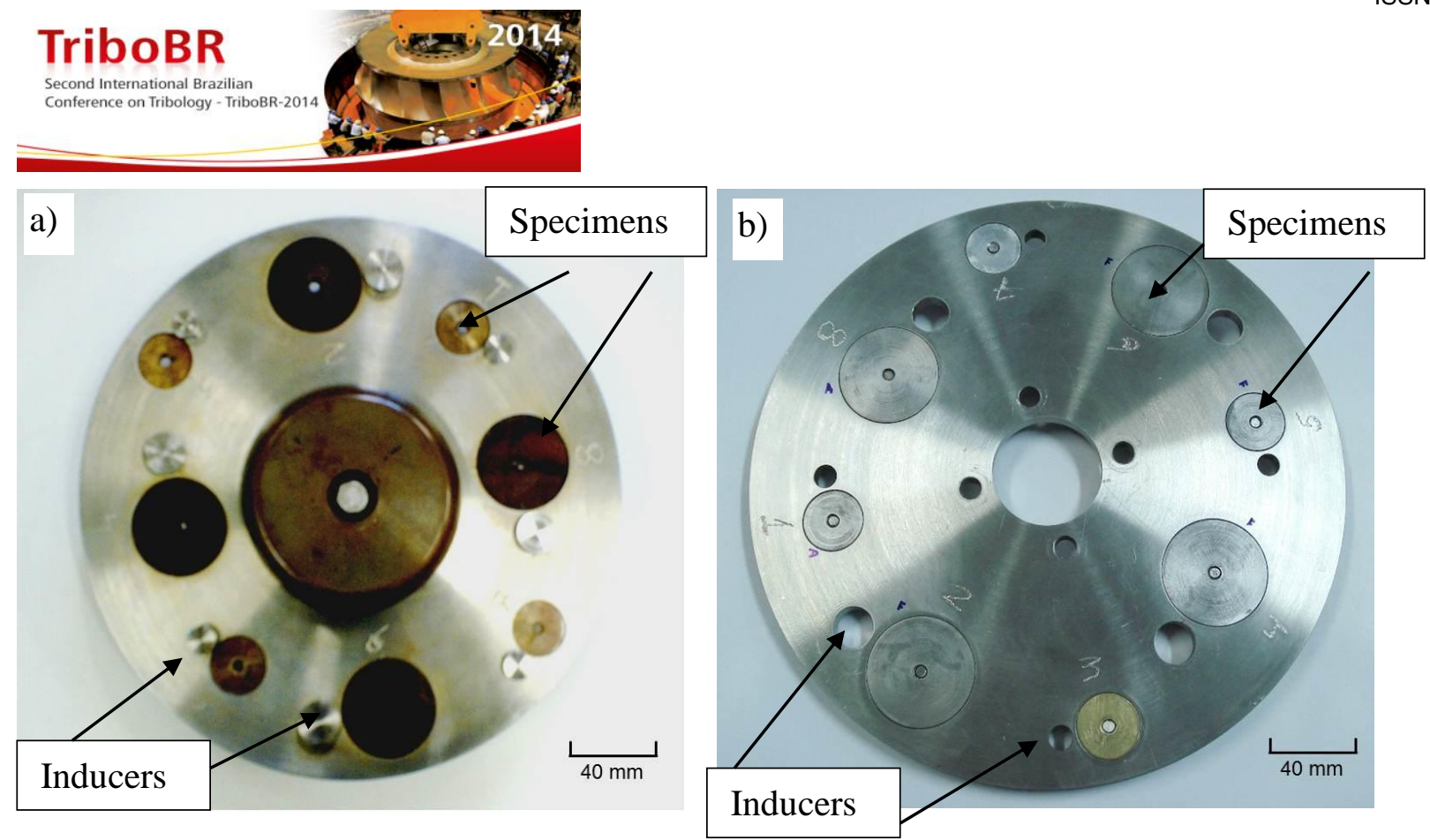

Figure 2. Rotating Disk photos, showing the specimens and bubble inducers positions: a) pins as bubble inducers and b) through-holes as bubble inducers.

\section{EXPERIMENTAL PROCEDURE}

In present experiments, discs of commercial aluminum, bronze, and common brass of diameter $2.54 \mathrm{~cm}$ and carburized cast iron of diameter $4.34 \mathrm{~cm}$ as specimens fixed on the rotating disk were tested. Eight specimens fixed on the rotating disk were employed in each test run as shown in Fig.2. The equipment was operated at 4400 rpm, resulting in a water flow average peripheral velocity at the specimen surface of $47.9 \mathrm{~m} / \mathrm{s}$ for specimens located at positions 3 and 7 in the disk, and average velocity of $43.7 \mathrm{~m} / \mathrm{s}$ for positions 2 and 6 , total testing time of 25 hours to obtain the results presented here. The experiments were performed at atmospheric pressure and the water temperature in the chamber was kept constant at $39^{\circ} \mathrm{C}$ by fresh tap water flow circulation for testing with rotating disk with holes as bubble inducers, and water temperature of $50^{\circ} \mathrm{C}$ for rotating disk with pins as bubble inducers. The operation conditions recorded for the electric motor and cavitation chamber is shown in Table 1 below.

Table 1. Equipment electric motor and cavitation chamber operation conditions

\begin{tabular}{ccccc}
\hline $\begin{array}{c}\text { Motor } \\
\text { speed } \\
(\mathrm{rpm})\end{array}$ & $\begin{array}{c}\text { Total Power } \\
\text { consumption } \\
(\mathrm{kw})\end{array}$ & $\begin{array}{c}\text { Effective } \\
\text { Power } \\
\text { consumption } \\
(\mathrm{kw})\end{array}$ & $\begin{array}{c}\text { Cavitation } \\
\text { inducer }\end{array}$ & $\begin{array}{c}\text { Water } \\
\text { temperature } \\
\left({ }^{\circ} \mathrm{C}\right)\end{array}$ \\
\hline 3600 & 10.2 & 9.6 & through-holes & 37 \\
\hline 4400 & 14.6 & 14.0 & through-holes & 39 \\
\hline 4400 & 23.0 & 22.4 & pins & 50 \\
\hline
\end{tabular}

Initially, the disc specimens used in these experiments had their chemical compositions determined by mass spectometer analysis. The specimen chemical compositions are listed in Table 2. In addition, Vickers micro-hardness (mHV) of test specimens were also obtained before testing and the experimental values are listed in Table 3.

* Technical contribution to the $2^{\text {nd }}$ International Brazilian Conference on Tribology - TriboBR 2014, November $3^{\text {rd }}$ to $5^{\text {th }}$, 2014, Foz do Iguaçu, PR, Brazil. 
Table 2. Chemical compositions of test specimens

\begin{tabular}{lcccccccccccc} 
Material & \multicolumn{10}{c}{ Chemical Element (weigth \%) } \\
\hline & $\mathrm{Pb}$ & $\mathrm{Zn}$ & $\mathrm{Sn}$ & $\mathrm{Al}$ & $\mathrm{Fe}$ & $\mathrm{C}$ & $\mathrm{Si}$ & $\mathrm{Cu}$ & $\mathrm{P}$ & $\mathrm{Mn}$ & $\mathrm{Mg}$ & $\mathrm{Ni}$ \\
\hline Cast iron & - & - & - & - & 93.01 & 3.80 & 2.52 & 0.49 & 0.05 & 0.04 & 0.03 & 0.01 \\
\hline Bronze & 14.90 & 5.60 & 3.07 & - & 0.09 & - & 0.01 & 76.13 & 0.01 & - & - & 0.19 \\
\hline Brass & 1.60 & 26.34 & 0.24 & 0.02 & 0.32 & - & 0.03 & 71.28 & - & 0.01 & - & - \\
\hline Aluminum & 0.01 & 0.02 & - & 98.24 & 0.22 & - & 0.45 & 0.16 & - & 0.22 & 0.68 & - \\
\hline
\end{tabular}

Table 3. Average Vickers micro-hardness of test specimens.

\begin{tabular}{cccccc}
\hline Material & Aluminum & Bronze & Cast iron & $\begin{array}{c}\text { Carburized } \\
\text { cast iron }\end{array}$ & Brass \\
$\begin{array}{c}\text { Vickers micro-hardness } \\
\text { (HV300gf) }\end{array}$ & 99.70 & 88.02 & 240.09 & 673.51 & 118.20 \\
\hline
\end{tabular}

After every 5 hours operating in cavitating conditions in the equipment, the test was stopped and specimens were removed from the rotating disk, cleaned by ultrasound, dried and weighted in a digital balance accurate to $0.1 \mathrm{mg}$ to obtain its mass loss in the cavitation erosion process. Photographs of damaged specimen surfaces were also obtained, using a scanning electron microscopy, SEM.

These new version of the rotating disk apparatus was effective in bubble formation, where it was possible to see cloud of bubbles inside the chamber (cavitation number was $\sigma=0.082$ ), as can be seen in Figure 1 .

\section{RESULTS AND DISCUSSIONS}

\subsection{Performance and Reproducibility of Present Equipment}

The operation conditions recorded and performance of present equipment was compared with similar apparatus which employed the rotating disk for cavitation erosion tests. Table 4 shows the characteristics of this equipment in comparison with other ones utilized by Rao et al. [7], Vivekananda et al. [8] and Zhiye [9]. Present equipment had the lowest power consumption when compared with other apparatus and the highest rotating speed.

In present cavitation erosion experiments, the cavitation number calculated by equation (1) varied from 0.077 to 0.098 which is compatible with bubble formation [10] observed in the experiments and well below the incipient cavitation number $\sigma_{i}$ of about 0.6 reported in the literature [3]. After 25 hours of operation in the cavitation chamber, mass loss of $37 \mathrm{mg}$ for brass specimen was observed.

Table 4. Performance comparison among the cativitation erosion apparatus

\begin{tabular}{ccccc}
\hline Author & $\begin{array}{c}\text { Electric motor } \\
\text { speed (rpm) }\end{array}$ & $\begin{array}{c}\text { Electric motor } \\
\text { power } \\
(\mathrm{kw})\end{array}$ & $\begin{array}{c}\text { Disk } \\
\text { diameter } \\
(\mathrm{mm})\end{array}$ & $\begin{array}{c}\text { Cavitation } \\
\text { inducer }\end{array}$ \\
\hline Present work & 4400 & 22 & 250 & through-holes \\
\hline Rao et al., 1980 & 2925 & 26 & 335 & pins \\
\hline $\begin{array}{c}\text { Vivekananda et } \\
\text { al., 1983 }\end{array}$ & 2880 & 26 & 335 & pins \\
\hline Zhiye, 1983 & 2950 & 30 & 350 & through-holes \\
\hline
\end{tabular}

\footnotetext{
* Technical contribution to the $2^{\text {nd }}$ International Brazilian Conference on Tribology - TriboBR 2014, November $3^{\text {rd }}$ to $5^{\text {th }}$, 2014, Foz do Iguaçu, PR, Brazil.
} 


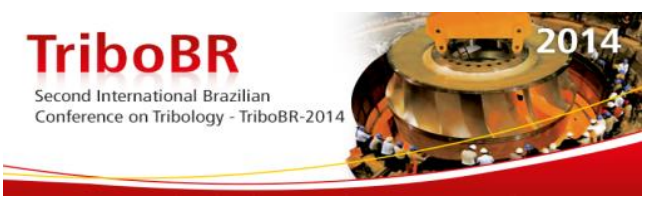

In order to check the equipment reproducibility, using through-holes as cavitation inducers, mass loss of brass was compared with other author's experimental results. Present experimental results of brass mass loss is close to those obtained by Rao et al. [7] and Vivekananda [8] who used a similar equipment, working with a rotating disk of $335 \mathrm{~mm}$ in diameter and using pins as cavitation inducers. Zhiye [9], on the other hand, used through-holes as cavitation inducers in a disk of $350 \mathrm{~mm}$ in diameter. The mass losses as well as the operating conditions can be analyzed in Figure 3 and Table 5, respectively.

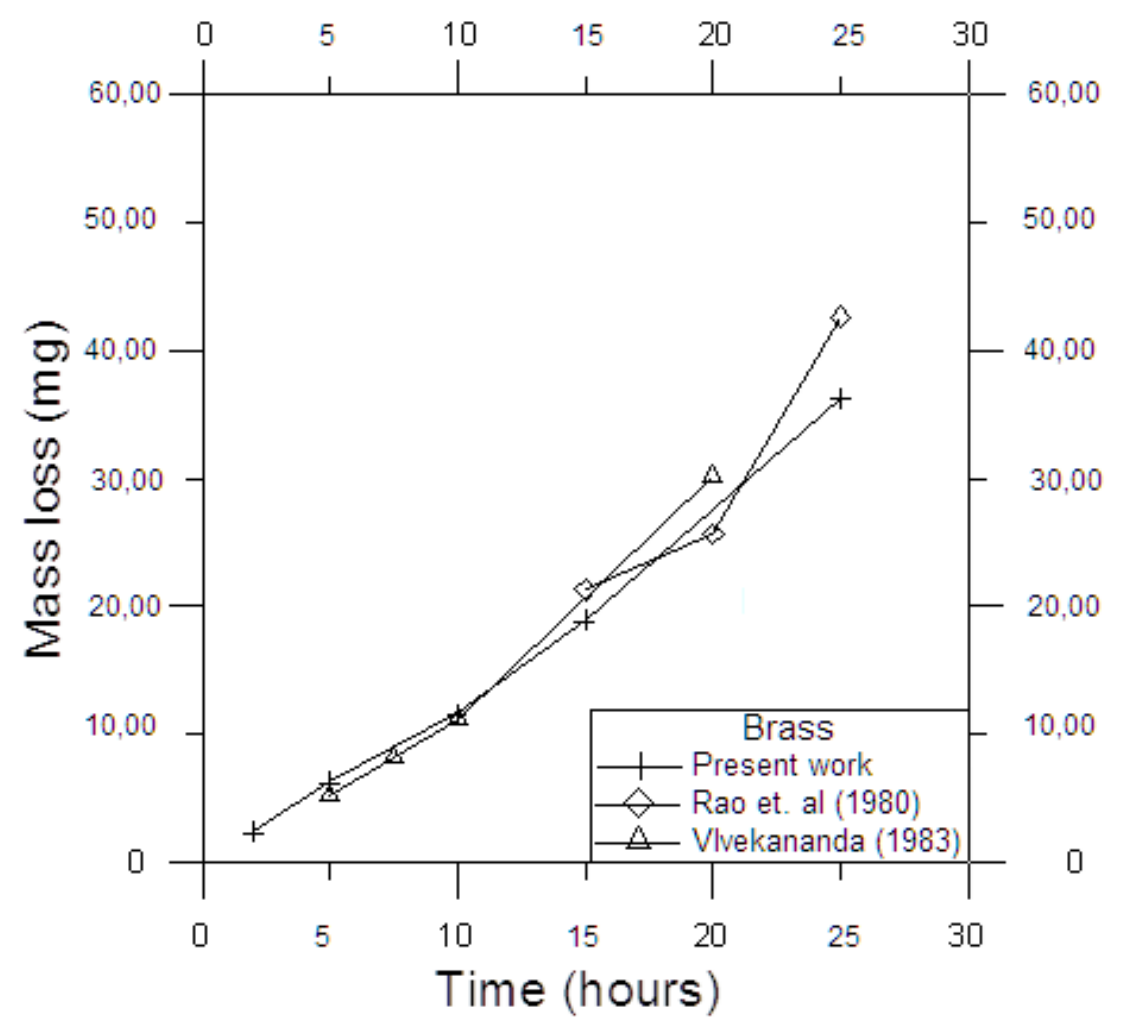

Figure 3. Comparison of mass loss with time for brass specimen under experimental cavitation erosion by different authors, using the rotating disk testing $[7,8]$.

Table 5. Comparison of mass loss of brass in rotating disk testing from various authors

\begin{tabular}{lcccc}
\hline \multicolumn{1}{c}{ Work } & $\begin{array}{c}\text { Mass loss } \\
(\mathrm{mg}) / \text { hours of } \\
\text { cavitating } \\
\text { condition }\end{array}$ & $\begin{array}{c}\text { Peripheral } \\
\text { velocity } \\
(\mathrm{m} / \mathrm{s})\end{array}$ & $\begin{array}{c}\text { Specimen } \\
\text { diameter } \\
(\mathrm{mm})\end{array}$ & $\begin{array}{c}\text { Chamber } \\
\text { temperature } \\
\left({ }^{\circ} \mathrm{C}\right)\end{array}$ \\
\hline Present work & $\begin{array}{c}6.2 / 5 \\
36.2 / 25\end{array}$ & 47.9 & 25.4 & 39 \\
\hline Rao et al., 1980 & $42.5 / 25$ & 53.8 & 63.5 & 34 \\
\hline Zhiye, 1983 & $5.8 / 4.2$ & 43.2 & not informed & 26 \\
\hline Vivekananda, 1983 & $30 / 20$ & 38.0 & 63.5 & 32 \\
\hline
\end{tabular}

For an exact comparison, all tests should be made in identical conditions, that is, the same inducers, equal peripheral velocity, and the same specimens (size and materials) as well as the same cavitation number $\boldsymbol{\sigma}$. Although Vivekananda [8] worked with greater specimen diameter $(63.5 \mathrm{~mm})$, they used smaller peripheral velocities $(38 \mathrm{~m} / \mathrm{s})$. Larger surface areas lead to a greater mass loss while smaller peripheral velocities have the opposite effect. Rao et al. [9] worked with greater

* Technical contribution to the $2^{\text {nd }}$ International Brazilian Conference on Tribology - TriboBR 2014, November $3^{\text {rd }}$ to $5^{\text {th }}$, 2014, Foz do Iguaçu, PR, Brazil. 


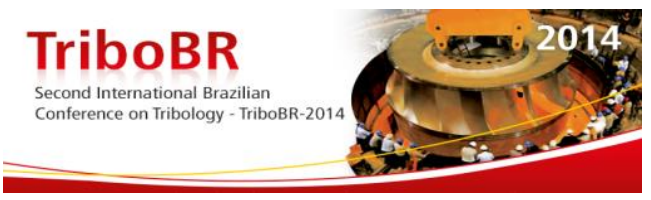

specimen diameters and greater peripheral velocities obtaining, as expected, a greater mass loss for the same period of time. Zhiye [9] conducted his experiments for 250 minutes only (approximate 4.2 hours), and the results are very close to the present work, although the specimens diameters are not informed in that work.

Therefore, present equipment reproducibility is quite good: mass loss by cavitation erosion in brass specimen was very similar to the results obtained by other authors [7, 8], but for exact comparison the same rotating disk operation conditions and materials should be used. For example, since one condition in the reference [7] has the tendency to increase the mass loss (greater specimen surface area), the other parameter has the opposite effect (smaller peripheral velocity).

The erosion mechanism in brass was analyzed by SEM surface photos. It is possibly due to the detachment of the weaker beta phase present in its microstructure which pattern is similar to the erosion pits pattern seen in the work by Bazanini and Bressan [6].

Concluding, in general, present equipment had quite good test reproducibility, using through-holes as cavitation inducers: the mass loss by cavitation erosion was the expected one for brass specimen, fitting well to those from the references $[7,8,9]$. In addition, present equipment had the lowest power consumption compared with the other devices and the highest rotating speed.

\subsection{Cavitation erosion diagrams of mass loss versus testing time}

The erosion rate of specimens with time under cavitating conditions in the rotating disk testing of present experiment are shown in Fig. 4 in diagrams of mass loss versus testing time for tested materials.
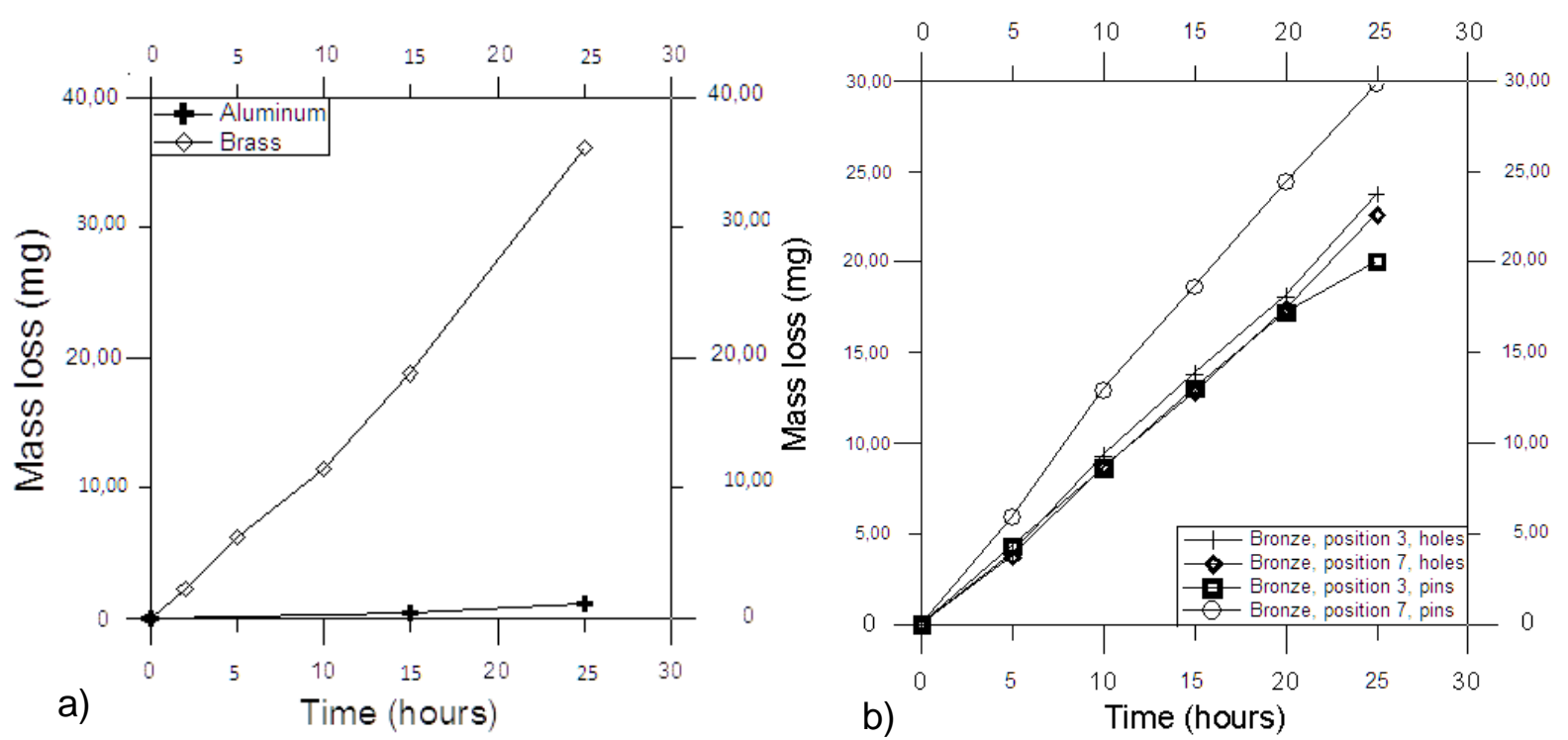

Figure 4. Comparison of mass loss curves in rotating disk testing: a) aluminum and brass specimens under cavitation erosion, using through-holes as cavitation inducers $\left(\mathrm{T}=39^{\circ} \mathrm{C} ; \sigma=0.082\right)$. b) bronze specimens under cavitation erosion rotating disk testing, using through-holes $\left(\mathrm{T}=39^{\circ} \mathrm{C}, \sigma=0.081\right)$ and pins $\left(\mathrm{T}=50^{\circ} \mathrm{C}, \sigma=0.077\right)$ in the disk as cavitation inducers.

For brass, the mass loss by erosion occurred as expected. However, for the softer aluminum specimen, it was expected a greater mass loss in relation to brass specimen, as can be seen in previous works in literature about cavitation erosion.

* Technical contribution to the $2^{\text {nd }}$ International Brazilian Conference on Tribology - TriboBR 2014, November $3^{\text {rd }}$ to $5^{\text {th }}$, 2014, Foz do Iguaçu, PR, Brazil. 


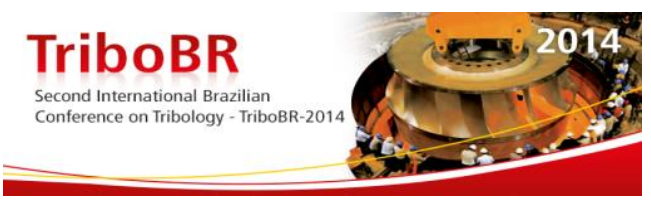

For the bronze specimens, both types of inducers were used in these experiments: through-holes and pins. Both kind of inducers caused erosion by cavitation. The curves of mass loss in function of working time in cavitation conditions obtained for these specimens are shown in Fig. 4b. The mass loss curves for bronze specimens under cavitation erosion and same position in the disk, but different bubble inducers, are presented. Through-holes as cavitation inducers presented better reproducibility. From the experimental results presented in Fig. 4b, it can be concluded that pins as cavitation inducers are more effective to produce mass loss by cavitation erosion than holes. However, the power consumption for running the disk with pins is almost double the cavitation using through-holes as bubble inducers.

For the carburized cast iron, it was not possible to detect the mass loss because, after a while, there is an increase in the specimen mass due to oxidation and also a mass loss by cavitation erosion, confirmed by the results in Figure 5.

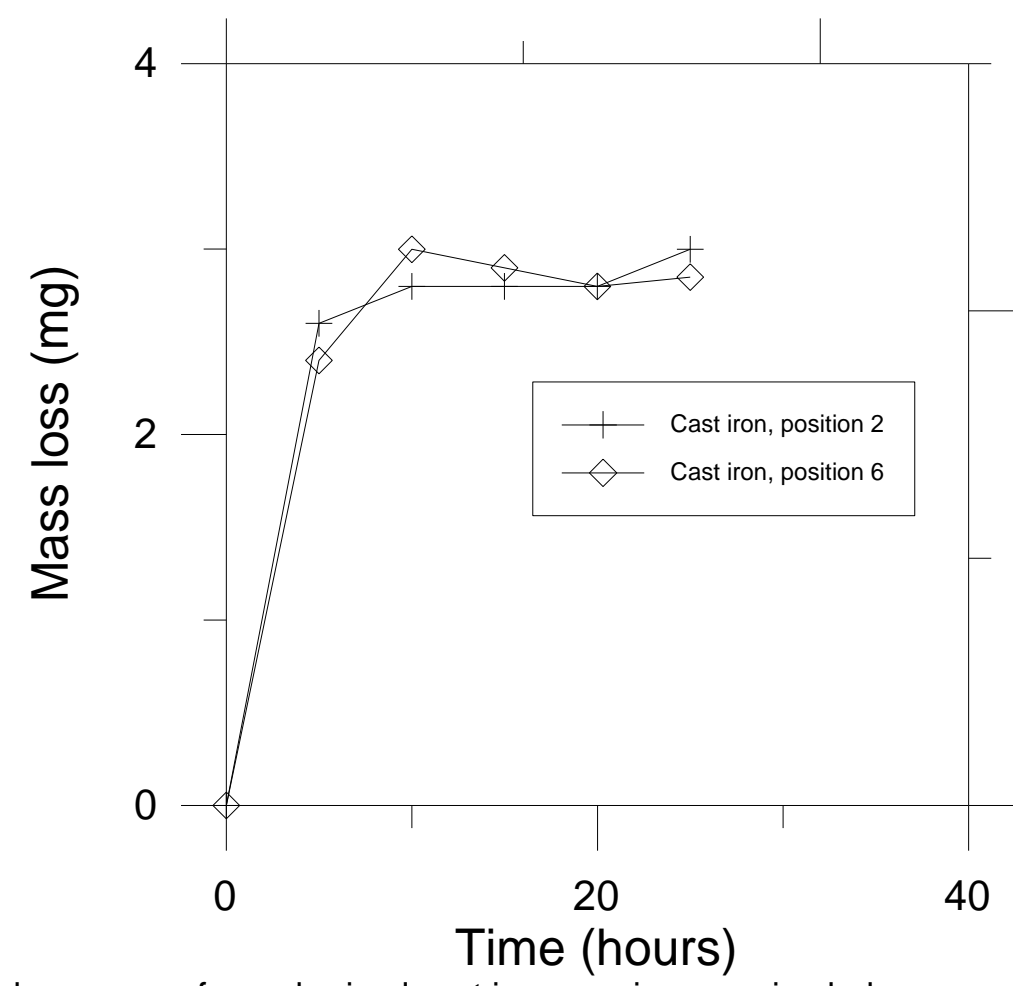

Figure 5. Mass loss curves for carburized cast iron specimens using holes as cavitation inducers.

\subsection{Mechanisms of Cavitation Erosion Observed by SEM During Testing}

All specimens surface damage and pit morphology were also analyzed by scanning electron microscope, SEM. Images of cavitation erosion obtained and pit morphology are shown in Figs. 6 to 10 below. Fig. 6a was obtained by SEM before erosion tests for aluminum specimens. Fig. 6b presents clearly the cavitation pits in aluminum surface due to micro-jets impingement after 5 hours of cavitation test. The pit diameter sizes varied from about 100 or $150 \mu \mathrm{m}$ or $150 \mu \mathrm{m}$ to around $300 \mu \mathrm{m}$ which is similar to the pit size reported by Haosheng [11], using rotating disk and iridescent color techniques.

Figure $7 \mathrm{a}$ and $7 \mathrm{~b}$ below shows cavitation pits in carburized cast iron and brass specimens surface respectively for 25 hours testing each specimen. For brass, it is possible to see large erosion area caused by the cavitation phenomena.

* Technical contribution to the $2^{\text {nd }}$ International Brazilian Conference on Tribology - TriboBR 2014, November $3^{\text {rd }}$ to $5^{\text {th }}$, 2014, Foz do Iguaçu, PR, Brazil. 


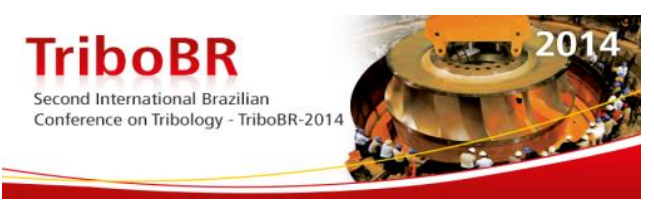

The region 1 in Fig. 7a for the carburized cast iron was employed for an EDS (energy dispersive spectrometer) analysis, to determine the chemical composition of the region 1 surface. The EDS analysis shows a great amount of oxygen element due to oxide formation on the cast iron surface and low chloride content from the chemical reaction with tap water, as expected.
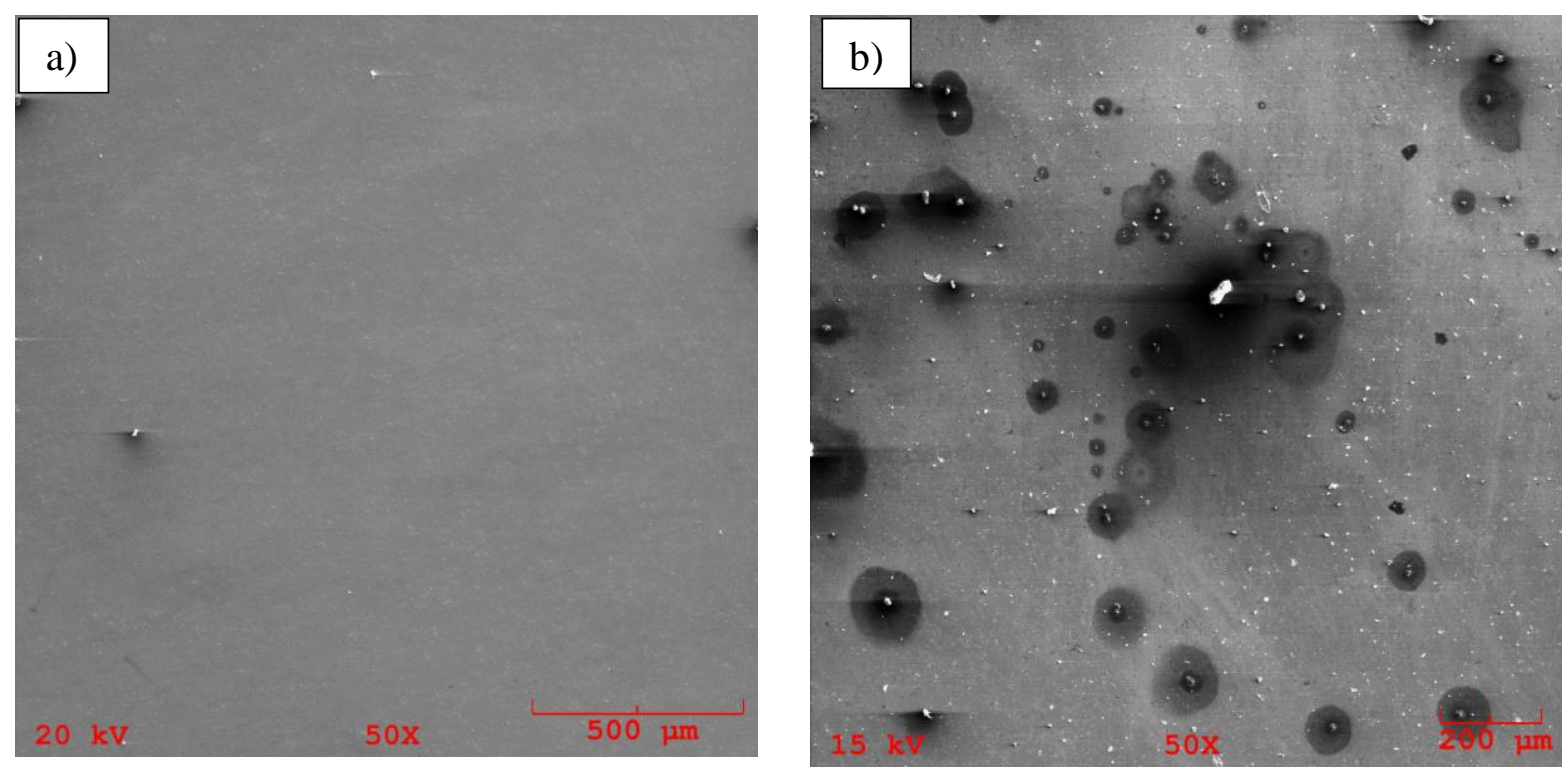

Figure 6. SEM photographs of aluminum specimen: a) before testing, magnification 50x. b) cavitation pits in aluminum surface, owing to jet impingement, magnification $50 x$, after 5 hours of cavitation test.
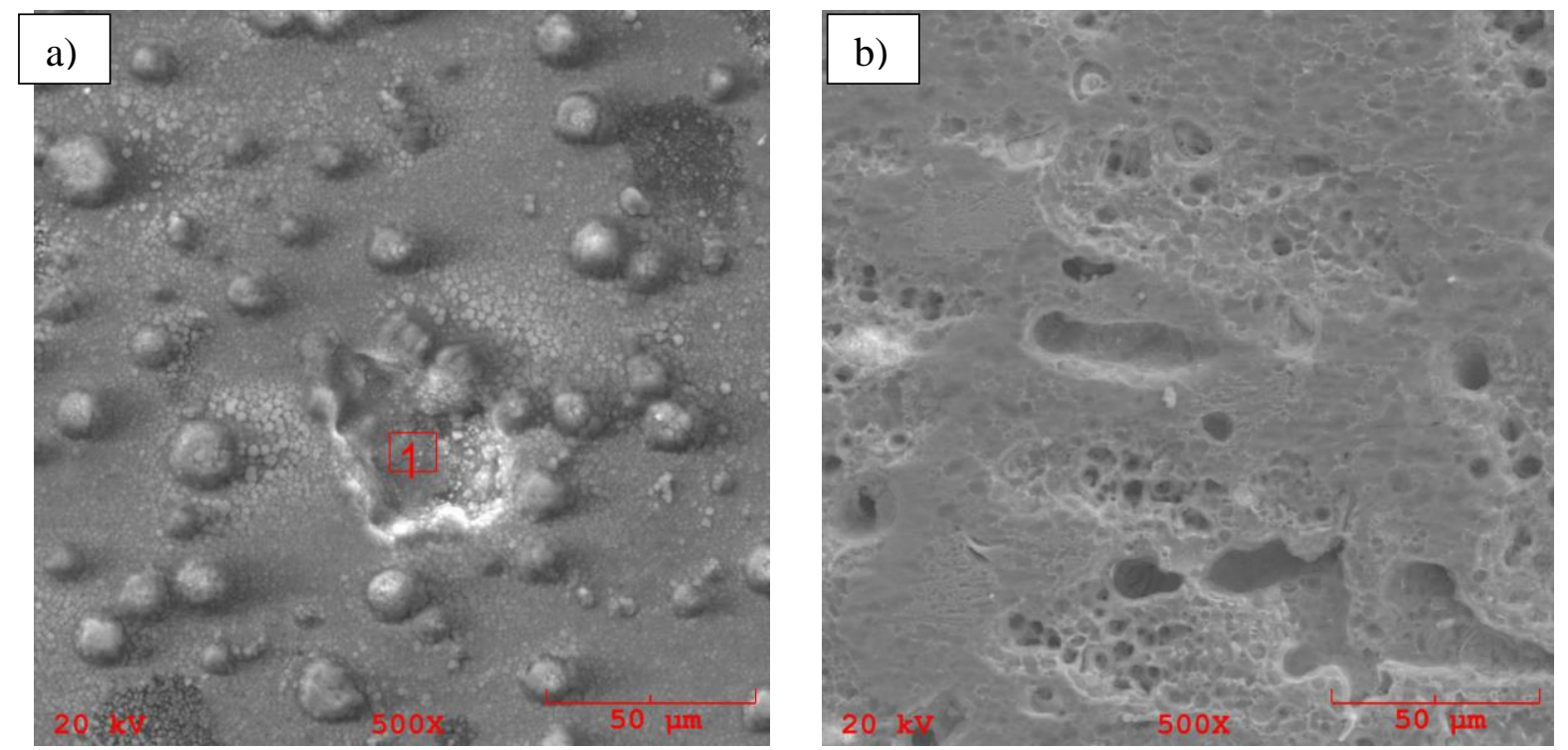

Figure 7. SEM photographs of cavitation pits: a) cavitation pit in carburized cast iron after 10 hours test, magnification 500x. b) cavitation erosion in brass surface, magnification 500x, after 25 hours test [6].

Figure 8 shows the SEM photographs of cavitation pits or burned area in aluminum specimen due to repetitive micro-jets impingement, after 5 hours cavitation testing. The pit diameter size was about $100 \mu \mathrm{m}$ to $150 \mu \mathrm{m}$. An EDS analysis was carried out on the aluminum specimen surface at regions 1, 2 and 3 shown in Fig. 8b. From the EDS analysis, It was possible to see a great amount of oxygen, especially on the pit region or burned area. Such high concentration of oxygen is possibly caused by alumina film formation and breaking due to local high temperature from micro-jets

* Technical contribution to the $2^{\text {nd }}$ International Brazilian Conference on Tribology - TriboBR 2014, November $3^{\text {rd }}$ to $5^{\text {th }}$, 2014, Foz do Iguaçu, PR, Brazil. 
impingement [3], resulting in resistance for further erosion or cavitation damage and negligible mass losses [9].
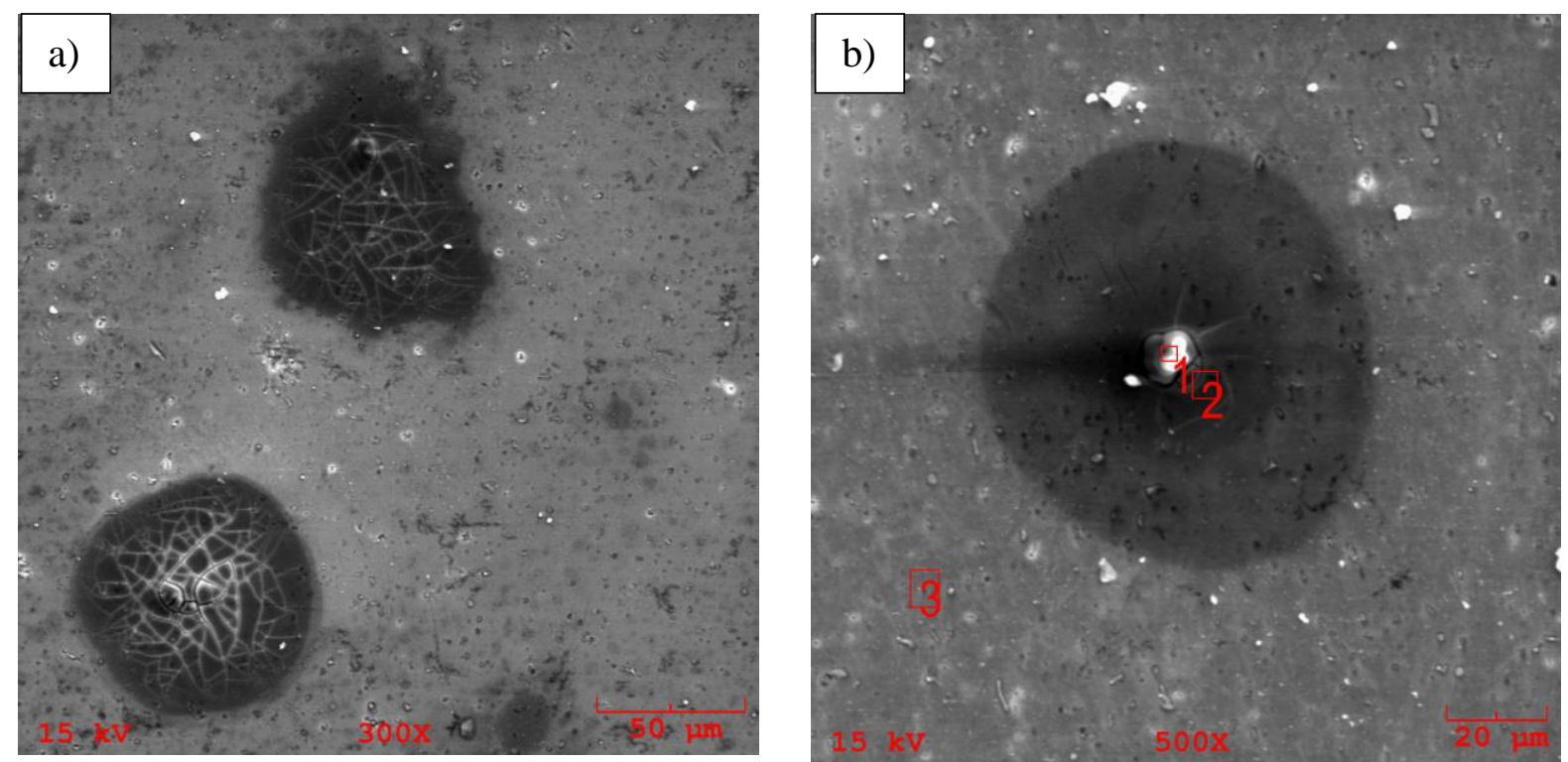

Figure 8. SEM photographs of cavitation pit in aluminum, after 5 hours cavitation testing. a) Magnification 300x. b) Magnification 500x, showing the burned region due to micro-jet impingement and the regions of EDS analysis areas 1, 2 and 3.

For aluminum specimens, the obtained experimental mass loss was very small and contrary to expected value of mass loss by cavitation erosion damage for softer materials reported in literature. The chemical composition and hardness of the aluminum and brass specimens were the expected ones, indicating that aluminum should be less resistant to cavitation erosion due to its lower hardness. However, SEM photographs and EDS analysis revealed burned circular craters due to micro-jet impingement and alumina, $\mathrm{Al}_{2} \mathrm{O}_{3}$, film formation and breaking. Hence, in the aluminum specimen it was not detected great mass losses, but it was possible to see the pitting formation of burned circular area. Cavitation damage without significant mass losses in aluminum alloy have been reported in the literature [9, 12].

Concluding, the erosion mechanism in aluminum specimen was caused by repetitive water micro-jet impacts perpendicular to the specimen surface with very low loss of mass due to alumina, $\mathrm{Al}_{2} \mathrm{O}_{3}$, film formation and hardening the surface, also hardening by plastic deformation, and posterior film breaking, as can be seen in Fig. 8. The burned circular craters were also possibly due to high temperature that has been attained.

Erosion by cavitation was also observed in the bronze specimens. Such erosion regions can be clearly seen in the sequence of images in Figs. 9 and 10, obtained by SEM photographs, for cavitating test time of 5,10 and 25 hours. It is possible to observe the initial surface porosity and the evolution of erosion pits with time of exposure of the specimen in the cavitating flow in rotating disk testing.

The cavitation erosion mechanism in brass and bronze was possibly due to flake detachment of the weaker beta phase present in its microstructure which is similar to the erosion pits pattern observed by SEM in Fig. 10 and the microstructure pattern reported by Bressan and Gil [6].

* Technical contribution to the $2^{\text {nd }}$ International Brazilian Conference on Tribology - TriboBR 2014, November $3^{\text {rd }}$ to $5^{\text {th }}$, 2014, Foz do Iguaçu, PR, Brazil. 

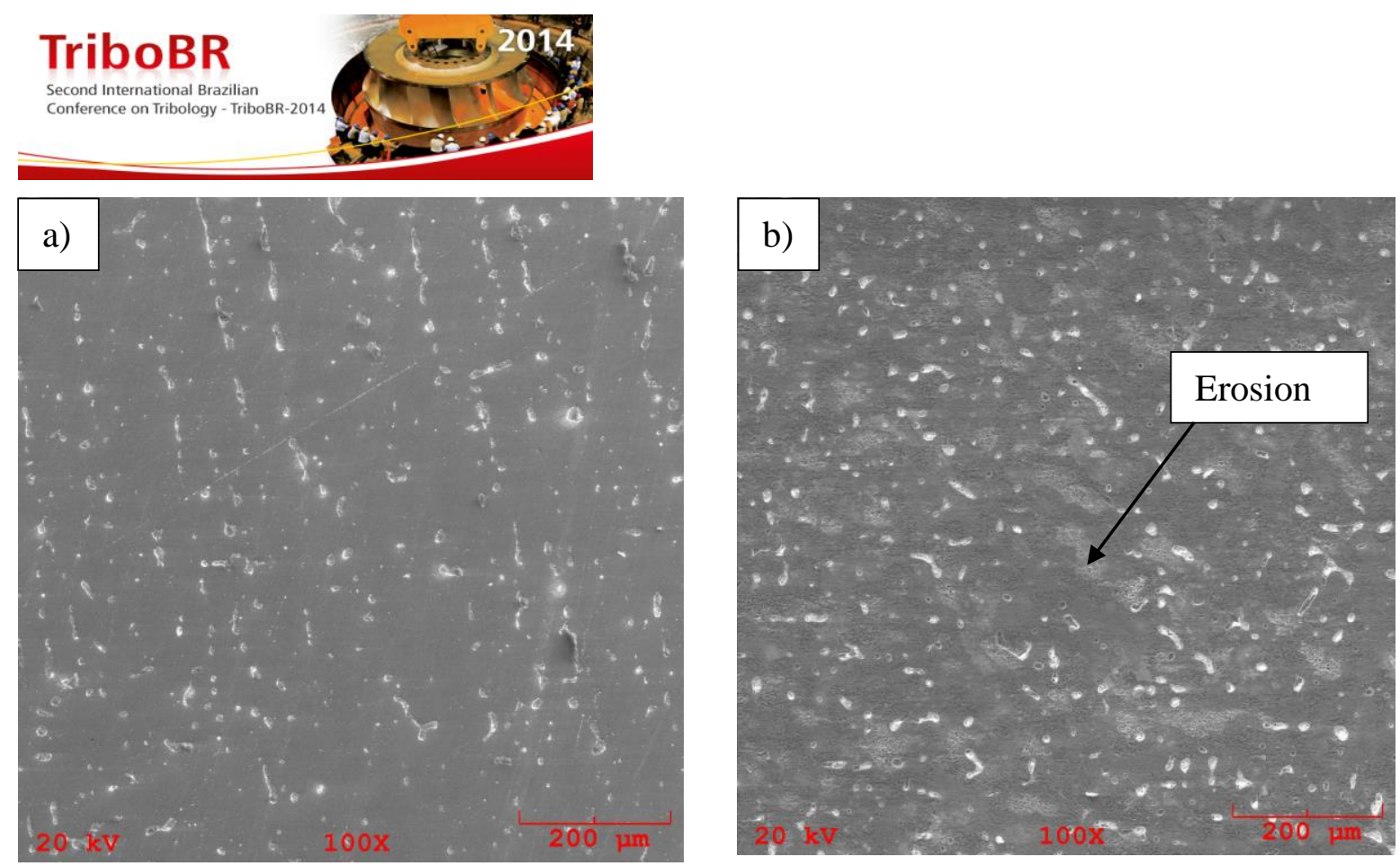

Figure 9. SEM photographs of cavitation pits: a) bronze specimen surface with initial porosity before testing, magnification 100x. b) bronze specimen after 5 hours testing showing the erosion marks and the initial porosity, magnification 100x.
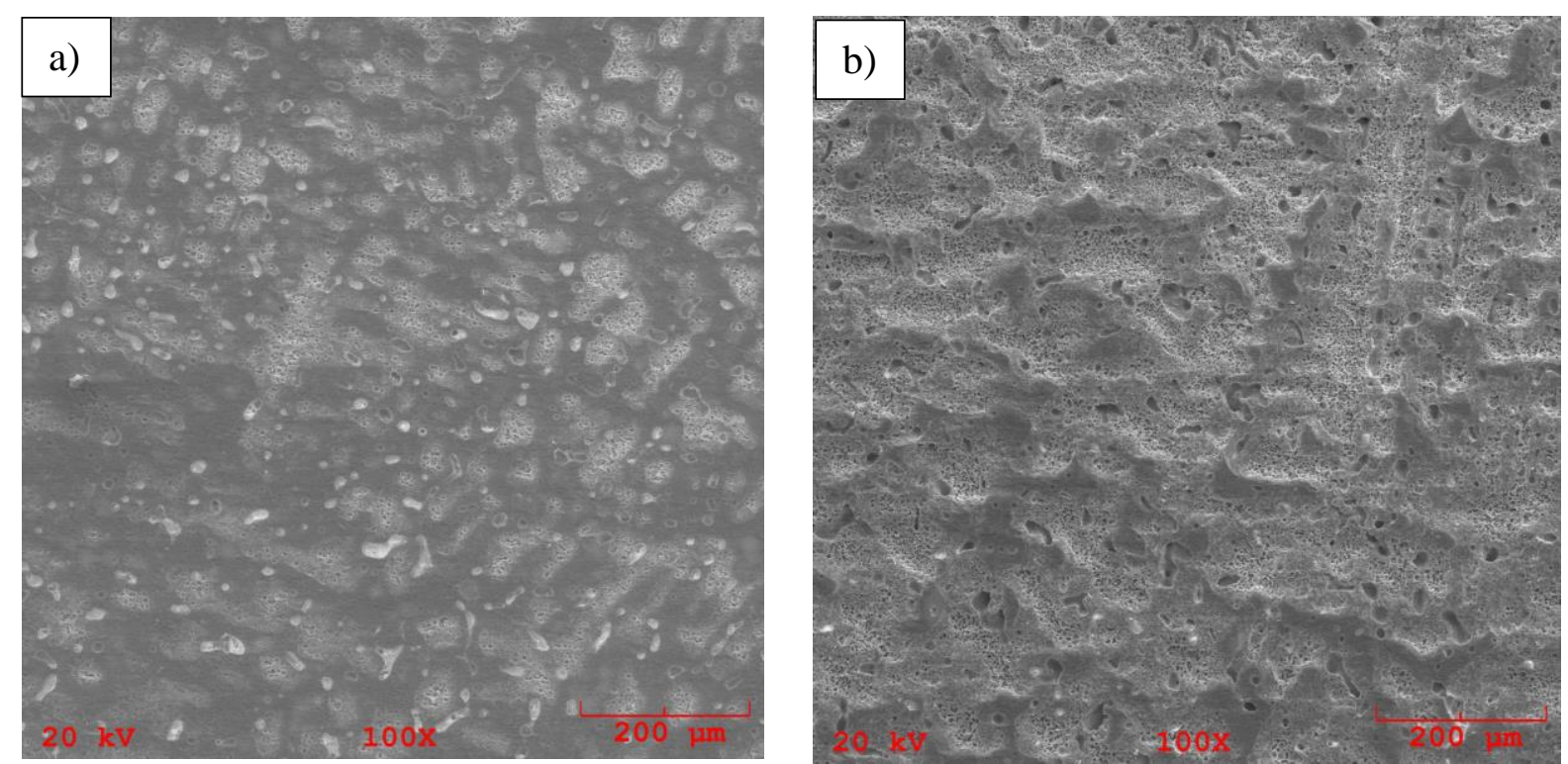

Figure 10. SEM photographs of cavitation pits in bronze specimen surface: a) after 10 hours testing, magnification 100x. b) after 25 hours testing, magnification 100x.

\section{CONCLUDING REMARKS}

From the experimental investigations and results on surface damage by cavitation erosion in aluminum, brass, bronze and cast iron specimens carried out in the new developed rotating disk laboratory equipment and comparison with other devices from literature, the following conclusions can be drawn,

a) The proposed new design of the compact rotating disk equipment [6] operated quite well in producing bubbles and cavitation erosion by micro-jets impingement in specimens at high peripheral speed of $47.9 \mathrm{~m} / \mathrm{s}$. No failure in the equipment occurred during its operation at constant 4400 rpm for 25 hours for each test specimen.

b) Present compact equipment had the lowest power consumption compared with the other devices and the highest rotating speed, as seen in Table 4.

* Technical contribution to the $2^{\text {nd }}$ International Brazilian Conference on Tribology - TriboBR 2014, November $3^{\text {rd }}$ to $5^{\text {th }}$, 2014, Foz do Iguaçu, PR, Brazil. 


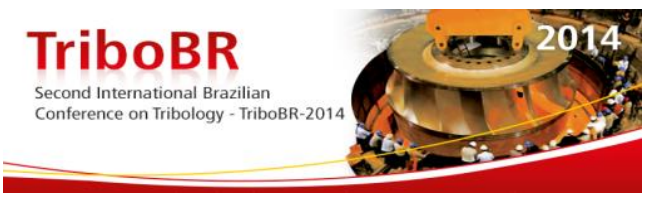

c) However, the measured effective power consumption depended on the kind of cavitation inducers: $14.0 \mathrm{~kW}$ when working with through-holes as cavitation inducers and $22.4 \mathrm{~kW}$ when working with pins.

d) Two main new advantages of the present equipment can be highlighted: up to eight specimens can be tested in one run and the compact design operates with no additional bearing to support the rotating disk.

e) All specimens presented surface damage: worn pits formation of about diameter size $100-300 \mu \mathrm{m}$, resulting from cavitation erosion, were observed by SEM in all specimens. Both bubble inducer types, pins and through-holes, caused the expected cavitation erosion in the tested metal specimen surfaces.

g) Present equipment had quite good test reproducibility, using through-holes as cavitation inducers (although a greater dispersion was observed when using pins as inducers): the mass loss by cavitation erosion was the expected one for brass specimen, fitting well to those found in the literature [10-12] for very similar operation conditions but different rotating disk equipment design.

\section{Acknowledgements}

The authors would like to gratefully thank the financial support received from FAPESC (Foundation for Research Support of Santa Catarina State), University of Santa Catarina State, CNPq of Brazil and Mr. Roberto Schneider and the Schneider Industries for technical support and worthy suggestions.

\section{REFERENCES}

1 Hammitt FG, Cavitation and Multiphase Flow Phenomena. McGraw-Hill Book Company, 1980.

2 Young FR, Cavitation. McGraw-Hill Book Company, 1989.

3 Brennen CE, Cavitation and Bubble Dynamics. Oxford University Press, 1995, pp.84.

4 Fujikawa S, T. Akamatsu T. On the Mechanisms of Cavitation Bubble Collapse. In: IAHR Symposium, Tokyo, Japan, 1980, pp. 91-102.

5 Shervani-Tabar MT, A. Rezaee-Barmi and S. M. S. Mahmoudi, Velocity Field and Pressure Distribution Around Two Parts of a Cavitation Bubble After its Splitting Near a Rigid Boundary. In: $5^{\text {th }}$ International Symposium on Cavitation, Osaka, Japan, 2003.

6 Bazanini G, Bressan JD. Preliminary Experience with a New Compact Disk Apparatus for Cavitation Erosion Studies. Wear, 2007; 263: 251-257.

7 Rao PV, Rao BCS, Rao NSL. Erosion and Cavity Characteristics in Rotating Components. J. Test. Eval., American Society of Testing and Materials, 1980: 127-142.

8 Vivekananda P. Mechanism of Cavitation Damage Influence of Stacking Fault Energy on Erosion and Erosion Resistance of Steels and Coatings. Ph.D. Thesis, Dept. of Civil Engineering, Indian Institute of Science, Bangalore, India, 1983.

9 Zhiye J. An Experimental Investigation on Cavitation Erosion for Propeller Alloys. China Ship Scientific Research Center Report, China, 1983.

10 Plesset MS, The Dynamics of Cavitation Bubbles. J. Appl. Mech., September, 1949: 277282.

11 Haosheng C, Iridescent Rings Around Cavitation Erosion Pits on Surface of Mild Carbon Steel. Wear,2010; 269: 602- 606.

12 ASM Handbook, Friction, Lubrication and Wear Technology, 1992; 18: 214-220.

* Technical contribution to the $2^{\text {nd }}$ International Brazilian Conference on Tribology - TriboBR 2014, November $3^{\text {rd }}$ to $5^{\text {th }}$, 2014, Foz do Iguaçu, PR, Brazil. 